\title{
CRÉDITO RURAL: SUSTENTABILIDADE E O PARADOXO DO DESENVOLVIMENTO ECONÔMICO SOCIAL DO CAMPO
}

\author{
RURAL CREDIT: SUSTAINABILITY AND THE PARADOX OF THE \\ SOCIAL AND ECONOMIC DEVELOPMENT OF THE FIELD
}

\author{
Arthur Prudente Campos Souza Veras ${ }^{1}$ \\ Carlos Eduardo Silva E Souza ${ }^{2}$
}

\section{RESUMO}

Considerando que o crédito rural possui um papel relevante na modernização e operacionalização do campo mediante o fomento das atividades agropecuárias, possibilitando o desenvolvimento econômico social da zona rural, objetiva-se pelo presente artigo, demonstrar que o instituto em franca evolução, de uma anterior primazia pela operacionalização e modernização das técnicas de exploração agrícola e pastoril, visando um maior rendimento, passa-se com o tempo a se ter uma primazia pela sustentabilidade do campo ante a criação dos programas de auxílio a agricultura familiar e seus fundamentos. Assim, mesmo que temporalmente desconexos, entende-se que os objetivos da sustentabilidade e do desenvolvimento econômico social do campo possuiriam o objetivo comum de beneficiar o produtor rural. Entretanto, tem-se que haveria um paradoxo entre ambos, já que o crédito rural é tomado como o principal responsável pela expansão agrícola na década de 70 , bem como pelo fato do Brasil ser hoje uma potência mundial no agronegócio, o que abarcaria também a degradação do meio ambiente ocorrida desde então.

Palavras-Chave: Exploração agrícola; Fomento; Sustentabilidade; Desenvolvimento econômico-social.

\footnotetext{
1 Mestrando em Direito Agroambiental pela Universidade Federal de Mato Grosso -UFMT, Mato Grosso,(Brasil). Especialista em Direito Administrativo e Administração Pública pela UFMT. Advogado.

E-mail: arthurveras.adv@gmail.com

${ }^{2}$ Mestre em Direito pela Universidade Federal de Mato Grosso - UFMT, Mato Grosso, (Brasil). Professor da FD/UFMT. Líder do Grupo de Pesquisa de Direito Civil Contemporâneo da FD/UFMT. Coordenador Pedagógico da ESA/MT. Advogado. E-mail: professorcarloseduardo@gmail.com
} 


\section{ABSTRACT}

Considering that rural credit has an important role in the modernization and operation of the field by the promotion of agricultural activities, enabling the countryside social and economic development, the objective by this article, is to demonstrate that the institute in frank evolution of an earlier priority for the operation and modernization of farming techniques and pastoral seeking a higher yield, has gone up over time to have a priority for the sustainability of the field by the creation of aid programs for family agriculture and its foundations.So even if the means are temporally disjointed, it is understood that the objectives of sustainability and social economic development of the field would possess the common goal of benefiting the farmers, however, certainly there would be a paradox between them, since the rural credit is taken as the principal by agricultural expansion in 70s, as well by the fact that Brazil is now a world power in agribusiness, which also encompass the environment degradation that has occurred since then.

Keywords: Agricultural holding; Fomentation; Sustainability; Social and economic development.

\section{INTRODUÇÃO}

Como instrumento de política pública, o instituto do crédito rural influenciou diretamente a expansão das fronteiras agrícolas pelo país, fomentando a produção e operacionalizando a agricultura em larga escala.

Entretanto, não tem incorporado dimensões grandes de sustentabilidade de maneira central, a despeito de iniciativas pontuais, no que tange aos programas de fomento a agricultura de rotatividade e programas de incentivo a agricultura familiar.

O presente artigo tem, por objeto, a análise do instituto do crédito rural, institucionalizado oficialmente pela Lei $\mathrm{n}^{\mathrm{o}}$. 4.829/65, que colimou a operacionalização do campo, possibilitando a beneficiação do produtor rural e o desenvolvimento econômico social do meio rural.

Pelo contexto atual da sociedade global que se depara com a necessidade de uma maior proteção da higidez ambiental, vê-se que o instituto em franca evolução, passou a observar também uma primazia pela sustentabilidade do campo.

Assim, pretende-se analisar o paradoxo demonstrado entre as finalidades do referido instituto como política pública fomentadora da agropecuária, já que, por um lado, visa-se precipuamente a operacionalização do meio rural e a melhoria das condições de rendimento da exploração agrícola e pastoril e, por outro norte, pretende-se também a utilização dos recursos naturais com extrema racionalidade, visando-se a sustentabilidade do campo, denotando-se o conflito de um fim em relação ao outro.

Desta feita, aliada a urgência de uma política de sustentabilidade visando à higidez ambiental e em virtude da necessidade reconhecida pela sociedade global, bem como pelos 
preceitos colimados na legislação interna de primazia do meio ambiente ecologicamente equilibrado, tem-se que a adoção de critérios ambientais na concessão do crédito serviriam como incentivo aos produtores rurais a seguirem a legislação socioambiental, deixando de ser uma estratégia de nicho ligada somente aos setores da agricultura familiar ou de pequena escala, para que se torne uma regra de conduta a ser seguida por todos.

Com essas perspectivas, o presente estudo encontra-se dividido em quatro partes, sendo que, na primeira delas, busca-se analisar a função social do crédito rural, discorrendo sobre o referido instituto desde a sua oficialização por lei no período da ditadura militar e sua distinção com os créditos comerciais comuns.

Em seguida, na segunda parte do artigo, descreve-se a função privativa do crédito rural, mediante a ideia de que o crédito presente na cártula, seria de uma maior importância que o próprio título em si.

Em um terceiro momento, analisa-se a natureza jurídica do crédito rural, distinguindo-o das demais operações de mercado, além de se buscar apresentar as suas peculiaridades.

E a última parte do artigo, dedica-se a análise do paradoxo existente atualmente, entre a aplicação ou concessão do crédito rural com base no princípio da sustentabilidade e o fomento objetivando o desenvolvimento econômico e social do campo em sua forma original como disposta na legislação. Nesta mesma parte, discorre-se também sobre as possibilidades futuras de uma utilização do crédito rural como incentivo aos produtores rurais a seguirem a uma legislação socioambiental, apontando que tal medida, tende a apresentar vantagens tanto para o produtor rural, como para o setor financeiro.

A investigação realizada norteou-se pela pesquisa bibliográfica e documental, mediante os métodos de abordagem qualitativo e dedutivo da análise dos dados, de forma a estruturar da melhor forma a pesquisa ora apresentada.

\section{A FUNÇÃO SOCIAL DO CRÉDITO RURAL}

Institucionalizado oficialmente pela Lei $\mathrm{n}^{\circ} .4 .829 / 65^{3}$ em plena ditadura militar, por meio do Programa de Ação Econômica do Governo (PAEG), o crédito rural, teve como principal escopo, procurar alavancar a operacionalização do campo moldando-se um novo projeto para a agricultura nacional, com base na produção agrícola visando o desenvolvimento econômico e o bem-estar social.

Historicamente, registra-se como marco inicial do crédito rural a Lei no ${ }^{\circ} 454 / 37^{4}$, a qual autorizava o Poder Executivo a conceder ao Banco do Brasil a permissão para prestar assistência financeira à agricultura, criação e às indústrias de transformação que trabalhassem com as matérias-primas do país, denominando-se o crédito à época, como "Carteira de Crédito Agrícola e Industrial".

\footnotetext{
${ }^{3}$ BRASIL. Lei $\mathbf{n}^{\mathbf{0}}$ 4.829, de 5 de novembro de 1965. Institucionaliza o crédito rural. Disponível em <http://www.planalto.gov.br/ccivil_03/leis/L4829.htm>. Acesso em 1 set 2016.

${ }^{4}$ BRASIL. Presidência da República. Lei $n^{\circ}$ 454, de 9 de julho de 1937. Autoriza o Tesouro Nacional a subscrever novas ações do Banco do Brasil, até a importância de 100.000:000\$000, e a emitir "bonus" para financiamento da agricultura, criação e outras indústrias. Disponível em <http://www.planalto.gov.br/ccivil_03/LEIS/1930-1949/L0454.htm>. Acesso em 1 set 2016.
} 
No entanto, as operações que o Banco do Brasil podia realizar, à época, de certa forma, limitavam-se às operações de "crédito de exercício" e "crédito de melhoria das condições de rendimento da exploração agrícola e pastoril".

Posteriormente, enxergando a necessidade do desenvolvimento nacional e a própria importância de uma linha de crédito especializada para o setor agropecuário que beneficiasse o produtor rural e possibilitasse o desenvolvimento econômico social do campo, foi promulgada a Lei $\mathrm{n}^{\mathrm{o}}$. 4.829/65, que institucionalizou o atual Crédito Rural, que acabou por se constituir em um importante marco histórico.

Anteriormente à promulgação da referida lei, outras normas antecedentes também merecem especial atenção, dada a sua importância para o setor e para o instituto do crédito rural, como por exemplo, o Decreto $\mathrm{n}^{\mathrm{o}}$. $22.626 / 33^{5}$, conhecido como a Lei de Usura, que acabou por fixar a taxa de juros nos contratos de natureza agrícola, em $6 \%$ ao ano.

Ao se discorrer sobre o crédito rural, sempre tem que se ter em mente que não se trata de um crédito comercial comum, tendo em vista ser disciplinado por uma legislação específica, diferentemente dos outros modelos de financiamentos bancários.

Tal diferenciação se impõe a partir da leitura do art. $1^{\circ}$ da Lei $n^{\circ} .4 .829 / 65$, a qual denota a finalidade principal do crédito rural, como sendo o bem-estar do povo, mediante o desenvolvimento da produção rural no País.

Pela própria disposição supra, tem-se que o crédito rural não pode ser confundido com um crédito comercial, tendo em vista a sua natureza eminentemente social.

Ao disciplinar o instituto do crédito rural, o legislador visou precipuamente o desenvolvimento da produção rural do País, levando-se em conta o bem-estar do povo, denotando-se assim o latente caráter social expressado na lei, não obstante as suas partes figurantes possuam ainda interesses de cunho privado.

O crédito rural possui um papel de suma importância na conjuntura das medidas governamentais denominadas de política agrícola, e de tão relevante a sua função, Benedito Ferreira Marques pontua que se pode dizer, sem receios da crítica especializada, que o crédito rural está para a política agrícola, assim como a função social está para o Direito Agrário. ${ }^{6}$

Ademais, é função de o Estado assegurar o bem-estar do cidadão, vide a própria primazia da função social, em relação à propriedade, contida na Constituição Federal.

O legislador constituinte de 1988 optou por incluir, no texto constitucional, a disciplina da política agrícola, que, por sua vez, regulamentada pela Lei $\mathrm{n}^{\circ}$. 8.171/91 ${ }^{7}$, delimitou o crédito rural como sendo um instrumento de financiamento da atividade rural, conforme o seu art. 48, delimitando que o mesmo fosse suprido por todos os agentes financeiros sem discriminação entre eles, mediante aplicação compulsória, com recursos próprios livres, dotações das operações oficiais de créditos, fundos e quaisquer outros recursos.

Ao se fazer presente no texto da Constituição Federal, denota-se a grande importância da política agrícola para o País, que assim confessou a sua vocação econômica.

\footnotetext{
${ }^{5}$ BRASIL. Presidência da República. Decreto $\mathbf{n}^{\mathbf{0}}$ 22.626, de 7 de abril de 1933. Dispõe sobre os juros nos contratos e da outras providencias. Disponível em <http://www.planalto.gov.br/ccivil_03/decreto/d22626.htm>. Acesso em 1 set 2016.

${ }^{6}$ MARQUES, Benedito Ferreira. Direito agrário brasileiro. 11. ed. rev. e ampl. São Paulo: Atlas, 2015. p. 152153

${ }^{7}$ BRASIL. Presidência da República. Lei no ${ }^{\circ}$ 8.171, de 17 de janeiro de 1991. Dispõe sobre a política agrícola. Brasília, 17 de janeiro de 1991. Disponível em: <http://www.planalto.gov.br/ccivil_03/leis/L8171.htm>Acesso em: 10 jul. 2016.
} 
Imperioso ainda se ressaltar o teor do art. $2^{\circ}$ da Lei $n^{\circ} .4 .829 / 65$, a qual define o crédito rural como "o suprimento de recursos financeiros por entidades públicas e estabelecimentos de crédito particulares a produtores rurais ou a suas cooperativas para aplicação exclusiva em atividades". 8

Assim, tem-se que o crédito rural se define como uma modalidade de crédito, com juros subsidiados pelo governo federal, que primaria pelo fortalecimento do produtor rural e o incremento de sua produção, no caso, as atividades que se enquadrariam na legislação.

Contudo, com uma grande diferenciação no que tange à sua finalidade, já que, conforme expressado anteriormente, o crédito rural possui a destinação para o fortalecimento do campesino, funcionando como um instrumento de realização do bem-estar social, que se traduz na manutenção da tranquilidade social, visando também, a promoção do interesse privado de seu tomador.

\section{A FUNÇÃO PRIVATIVA DO CRÉDITO RURAL}

O texto legal, que institucionalizou o crédito rural, trouxe em seu art. $1^{\circ}$, que o fim supremo buscado pelo fomento subsidiado pelo Governo Federal seria o bem-estar do povo, além de se prestar ao desenvolvimento da produção rural do país.

Nítida foi a preocupação do legislador em possibilitar o pretendido desenvolvimento, sem desamparar a atividade rural quanto aos recursos financeiros que o produtor necessitaria, conforme a prescrição do próprio art. $3^{\circ}$, inciso III da Lei $4.829 / 65$, que dispõe que o crédito rural deve proporcionar o custeio oportuno e adequado da produção e a comercialização de produtos agropecuários. ${ }^{9}$

Nesse sentido, pela ideia de primazia de auxílio ao produtor, tem-se que a finalidade do crédito rural, em momento algum, será o ganho do emprestador, mas, de modo contrário, o fortalecimento do tomador.

Logo, o crédito rural possui uma finalidade privada, e esta, volta-se ao interesse do financiado e não do financiador, de modo que o crédito presente na cártula de crédito rural possuir maior importância que o próprio título.

Nesse sentido, importante trazer a afirmação de Lutero de Paiva Pereira, sobre a questão que corroboraria a noção de que o título em si teria menor importância que o crédito contido na cártula:

Não se nega que a cédula de crédito rural dê segurança creditícia ao financiador. O que se afirma, no entanto, é que o crédito nela presente tem maior importância do que o próprio direito que o título contempla, sendo certo afirmar que, por se tratar de crédito rural, o título se

\footnotetext{
${ }^{8}$ BRASIL. Presidência da República. Lei $n^{\circ}$ 4.829, de 5 de novembro de 1965. Institucionaliza o crédito rural. Brasília, 5 de novembro de 1965. Disponível em: <http://www.planalto.gov.br/ccivil_03/leis/L4829.htm>Acesso em: 11 jul. 2016.

${ }^{9}$ Idem.
} 
submete aos preceitos do financiamento e não o financiamento aos preceitos do título. ${ }^{10}$

Logo, não se pode admitir que, em uma eventual questão de cobrança, o intérprete da lei utilize-se de entendimentos que desfavoreçam as máximas da função social do próprio crédito, consubstanciada no fortalecimento econômico do produtor rural, no caso o tomador.

Desse modo, em se tratando de crédito rural, os princípios do Direito Civil (lei especial) não se sobrepõem aos ditames de eventual legislação geral, pois, pelo contrário, o financiamento em questão submeter-se-ia aos preceitos do título, contrariando a sua finalidade social.

À despeito disso, embora a legislação e a doutrina deem trato diferente ao crédito rural, registra-se pela jurisprudência que o crédito rural rotineiramente tem sido tratado como um crédito comercial, de modo que as decisões se afeiçoam mais ao interesse do emprestador, em detrimento do produtor rural, e como exemplo disso, vê-se pelo julgado colacionado abaixo, em que o Tribunal de Justiça do Rio Grande do Sul assentou pelo cabimento de multa moratória de $10 \%$, em relação ao inadimplemento do crédito concessionado:

\begin{abstract}
APELAÇÃO CÍVEL. NEGÓCIOS JURÍDICOS BANCÁRIOS. CÉDULA DE CRÉDITO RURAL, COMERCIAL E INDUSTRIAL. MULTA MORATÓRIA. POSSIBILIDADE. SENTENÇA REFORMADA. Consoante orientação emanada do Superior Tribunal de Justiça, é cabível a multa de $10 \%$, para os contratos envolvendo Cédula, rural, Comercial ou Industrial, e este é o caso dos autos, razão pela qual merece reforma a sentença, para determinar a manutenção da multa pactuada. DERAM PROVIMENTO AO APELO. UNÂNIME. (Apelação Cível No 70052268166, Décima Sexta Câmara Cível, Tribunal de Justiça do RS, Relator: Ergio Roque Menine, Julgado em 24/10/2013, Data de Publicação: Diário da Justiça do dia $28 / 10 / 2013) .^{11}$
\end{abstract}

Tais decisões acabam por desvirtuar a conceituação finalística do crédito rural, ante o tratamento análogo ao de um crédito comercial comum, como se o objetivo maior da institucionalização do crédito teria por fim, assegurar ao mutuante uma oportunidade de ganho financeiro.

Esse trato jurisprudencial vai de encontro ao que preceitua o art. $5^{\circ}$ da Lei de Introdução as Normas do Direito Brasileiro ${ }^{12}$, a qual determina que o julgador aplique a lei atendendo aos fins sociais a que ela se dirige, levando em conta as exigências do bem comum.

\footnotetext{
${ }^{10}$ PEREIRA, Lutero de Paiva. Crédito rural. In: QUEIROZ, João Eduardo Lopes et SANTOS, Márcia Walquiria Batista dos (Coords.). Direito do agronegócio. 2. ed. ampl. Belo Horizonte: Fórum, 2011. P.134.

${ }^{11}$ RIO GRANDE DO SUL. Tribunal de Justiça. Recurso de Apelação Cível no. 70052268166, Apelante: Estado do Rio Grande do Sul. Apelado: Helenita Regina Pfingstag e Outros. Porto Alegre, 24 de outubro de 2013. Disponível em: <http://tj-rs.jusbrasil.com.br/jurisprudencia/113446540/apelacao-civel-ac-70052268166rs/inteiro-teor-113446550>. Acesso em: 20 jun. 2016.

12 BRASIL. Presidência da República. Decreto-Lei 4657, de 4 de setembro de 1942. Acesso em <http://www.planalto.gov.br/ccivil_03/decreto-lei/Del4657compilado.htm>. Acesso em 1 set 2016.
} 
Como resultado, tem-se ao longo do tempo, uma herança negativa ao setor produtivo primário, que acabou por se endividar, do qual, por vezes, não consegue se livrar, a não ser que os débitos sejam revisados de forma pertinente.

Sobre a questão, Lutero de Paiva Pereira ${ }^{13}$ sinaliza a necessidade de uma retomada dos preceitos da legislação especial com o escopo de fazer uma autêntica purificação das arbitrariedades financeiras presentes nos contratos de fomento rural, com o fim de trazer a obrigação aos estreitos limites da lei especial, mesmo porque ninguém estaria obrigado a mais do que isto, em atenção ao art. 5, inciso II da Constituição Federal ${ }^{14}$.

Enfim, por suficiente a base explanatória de que o crédito rural não haveria de ser tratado como um crédito comercial, tendo em vista a sua clara finalidade, vê-se que há base suficiente para que se eleve o crédito rural a condição de crédito de função social, pelo atendimento dos fins sociais a que ele se dirige.

\section{A NATUREZA JURÍDICA DO CRÉDITO RURAL}

Como já dito, o crédito rural possui uma legislação específica que o institui e tem, como fonte de recursos, os fundos oficiais e constitucionais, diferentemente dos empréstimos comerciais, que possuem fundos de natureza diversa.

Embora se trate de um modo de financiamento realizado pelos agentes integrantes do sistema financeiro nacional, não é uma operação de mercado financeiro, por não se caracterizar, em sua própria essência, como uma operação de mercado.

Além disso, importante salientar também sobre a questão da modicidade dos juros no instituto do crédito rural, já que estes não estão afetos ao interesse e ao arbítrio do financiador, diferentemente das operações do mercado financeiro, já que sua taxa de juros anual é fixada em $6,75 \%$ ao ano, sendo que se forem concedidos no âmbito do Pronaf, podem variar de 1,0\% a $5,5 \%$ ao ano.

Há o entendimento de que o crédito rural seria de natureza eminentemente agrária por sua inquebrantável ligação às atividades agrárias e sua respectiva função social, com base nos princípios jusagraristas fundamentais, até porque, como sendo instrumento de política agrícola, deve realizar o fomento da produção agropecuária e servir à organização do abastecimento alimentar, que é dever do Poder Público. ${ }^{15}$

Ademais, tendo-se como base as legislações regulamentadoras da política agrária nacional, pode-se afirmar que o crédito rural se subordina às peculiaridades do ciclo biológico produtivo agrário e, em decorrência disso, enquanto operação creditícia fomentadora de atividade agrária, possui então natureza agrária.

Tal conceituação pode ser correlacionada por analogia, à própria definição dada as normas agraristas no direito brasileiro, haja vista que a doutrina as classifica simplesmente

\footnotetext{
${ }^{13}$ PEREIRA, Lutero de Paiva. Crédito rural. In: QUEIROZ, João Eduardo Lopes et SANTOS, Márcia Walquiria Batista dos (Coords.). Direito do agronegócio. 2. ed. ampl. Belo Horizonte: Fórum, 2011. p.136

${ }^{14}$ BRASIL. Presidência da República. Constituição da República Federativa do Brasil de 1988. Disponível em <http://www.planalto.gov.br/ccivil_03/constituicao/constituicaocompilado.htm>. Acesso em 1 set 2016.

${ }^{15}$ ALBUQUERQUE, Marcos Prado de. Crédito rural. Cuiabá: Ed. UFMT, 1995. p. 196
} 
como normas de caráter econômico-social, entretanto, como integradas pela própria finalidade, adquire uma natureza única, no caso a natureza jus-agrarista. ${ }^{16}$

Igualmente, pela afirmativa de que o fim essencial do crédito rural positivado pela Lei $n^{\circ} .4 .829 / 65$, é o atendimento da atividade rural por meio do fortalecimento do produtor visando o bem-estar social, tem-se que a natureza jurídica do instituto tema do presente estudo, é eminentemente agrária.

Contudo, importante salientar que, embora de natureza jus-agrarista em virtude de sua finalidade e pelo seu caráter econômico-social, o crédito rural quando cedido à União Federal, leva consigo a natureza privada, não podendo confundi-lo com o débito fiscal de caráter essencialmente público, de modo que, a União não poderia se valer do procedimento da execução fiscal, e na pretensa execução de créditos exigíveis e não quitados oriundos das cédulas de créditos rural, em respeito à legalidade, haveria de se utilizar da execução lastreada no Código de Processo Civil, observando-se o disposto no Decreto-Lei 167/67, e jamais, da execução fiscal. ${ }^{17}$

\section{O CRÉDITO RURAL E SUA APLICAÇÃO COM BASE NO PRINCÍPIO DA SUSTENTABILIDADE, E O DESENVOLVIMENTO ECONOMICO SOCIAL DO CAMPO}

As linhas de crédito rural instituídas pela Lei $n^{\circ}$. 4.829/65 são normatizadas pelo Banco Central do Brasil (BACEN), que é uma autarquia vinculada ao Ministério da Fazenda, cuja missão é a de assegurar a estabilidade do poder de compra da moeda e um sistema financeiro sólido e eficiente.

Tais linhas se subdividem em duas vertentes: a primeira direcionada para a agricultura familiar e os programas de reforma agrária, e a segunda voltada para a agricultura empresarial.

No caso da agricultura familiar, que é constituída por pequenos e médios produtores rurais, foi criado o Programa Nacional de Fortalecimento da Agricultura Familiar (PRONAF), responsável pelo fomento de projetos individuais ou coletivos, que gerem renda aos pequenos produtores e aos assentados, possuindo as taxas mais baixas de juros.

De outro norte, a agricultura empresarial é aquela realizada profissionalmente, onde o agricultor age como um empresário e utiliza-se de tecnologia e certa capacitação na produção.

Em ambas as sistemáticas, impactos sociais e ambientais são sempre avaliados nos projetos de financiamento a serem concedidos, e para a concessão do crédito rural há de ser analisada a sustentabilidade da empreitada.

Desde a instituição do crédito rural e, principalmente, após a Constituição Federal de 1988, que positivou o princípio da sustentabilidade, a preocupação com o desenvolvimento sustentável se insurgiu nas concessões do fomento, com a ideia de se suprir as necessidades da geração atual, sem comprometer a capacidade de atender as necessidades das gerações

\footnotetext{
${ }^{16}$ Ibidem. p. 204.

${ }^{17}$ FORSELINI, Yuri John. A medida provisória 2.196-3, que transmudou a natureza jurídica da cédula de crédito rural e possibilitou sua cessão à União Federal. In: Revista Jurídica UNIGRAN/Centro Universitário da Grande Dourados. Dourados, MS. V. 12, n. 24, jul. /dez. 2010.
} 
futuras, prezando em manter os recursos para o futuro, pelos preceitos da equidade intergeracional e intrageracional. ${ }^{18}$

Isso porque, os problemas ambientais gerados por tomadores de créditos podem ter sérios impactos não somente por sobre o meio ambiente ecologicamente equilibrado, mas também no que tange a liquidez de débitos ou no próprio ganho de investidores.

Embora a finalidade precípua do crédito rural não abarque tais riscos à atividade bancária, por ter, como fim, o fortalecimento do produtor e o bem-estar social, a preocupação socioambiental também atinge a concessão do crédito rural.

Conforme as exigências do Banco Central do Brasil, a concessão do crédito rural no caso da agricultura familiar é vinculada aos elementos de sustentabilidade e possui critérios previamente definidos.

Por possuírem um viés socioambiental e juros mais acessíveis, com prazos e carência maior que as linhas tradicionais, as linhas do PRONAF Agroecologia e PRONAF Eco, visam dar maior viabilidade para pequenos produtores rurais em suas atividades desenvolvidas e integrar processos sustentáveis na propriedade por meio de tais fomentos. ${ }^{19}$

Contudo, paradoxalmente, o crédito rural seria auxiliou em muito no desenvolvimento econômico social do campo, mediante uma fácil constatação da evolução da tecnicidade e da própria produção agropecuária no país, desde a sua implementação.

A política de crédito rural teve um papel determinante na transformação da agropecuária nacional, financiando a infraestrutura e a mecanização necessárias, sendo talvez o principal responsável pela expansão do cultivo de soja na década de 1970 do Sul para o Centro-Oeste do Brasil, sendo até mesmo um caso emblemático dos efeitos socioambientais perversos que acompanharam o crescimento econômico impulsionado pelo crédito rural e pela própria tecnificação da agricultura. ${ }^{20}$

Ademais, a expansão do cultivo mecanizado da soja acabou por provocar o aumento do preço nas terras do Sul, aumentando assim a concentração fundiária e a migração de colonos para o centro-oeste e avanço da fronteira agrícola sobre o cerrado brasileiro. ${ }^{21}$

Acerca da questão, completa-se ainda que a opção de política pública pela aplicação do crédito rural e a tecnificação da agricultura priorizando uma agricultura intensiva em capital, acabou por contribuir para o aumento da legião de despossuídos no meio rural, mais especificamente na região sul. ${ }^{22}$

A partir de tais avanços, se concretizaria o colimado desenvolvimento econômico social no campo, com atividades concretas que possuiriam uma grande força motivadora, através do aumento da produção, da produtividade e da própria renda dos produtores rurais, entretanto, em contrapartida, por não se tratar de uma preocupação à época, sem prezar pela sustentabilidade.

\footnotetext{
${ }^{18}$ WEISS, Edith Brown. Our rights and obligations to future generations for the environment. In: The American Journal of International Law, vol. 84, n.1, jan. 1990. p. 40-43.

${ }^{19}$ WOJCIECHOWSKI, Ruan Cristian; LEITE, Anderson; SEHNEM, Simone; BERNARDY, Rógis. Análise da concessão de crédito rural pelo BNDES vinculado aos elementos de sustentabilidade. Revista Estudos do CEPE, Santa Cruz do Sul, n. 40, P. 137-167

${ }^{20}$ IGARI, Alexandre T.; PIVELLO, Vânia R. Crédito rural e código florestal: irmãos como Caim e Abel. In: Ambiente \& Sociedade, São Paulo, v.14, n.1, 2011. p.145.

${ }^{21}$ Idem.

${ }^{22}$ Ibidem. p. 145.
} 
Portanto, embora o crédito rural imponha algumas exigências cruzadas, como a exigência à legislação florestal, sua principal prerrogativa é prover recursos à agricultura, não sendo desenhado para priorizar a sustentabilidade do setor, o que é uma necessidade e representa uma oportunidade para a agropecuária em território nacional. ${ }^{23}$

Porém, como dito antes, com novos arranjos institucionais, e com o direcionamento do crédito rural, às atividades que prezam pela sustentabilidade, como o próprio PRONAF, que visa o fomento de atividades florestais sustentáveis no âmbito da agricultura familiar, a tendência é a mudança para que seja dada uma maior importância à sustentabilidade e a implementação de políticas socioambientais.

Atualmente, bancos privados como o Rabobank (banco holandês especializado no fomento de atividades relacionadas à alimentação e agro financiamento), já aplicam diversas políticas socioambientais anteriormente à concessão de créditos e financiamentos aos produtores rurais, sob a ótica de que quanto maior o risco ambiental do negócio, maior é o risco financeiro.

Aliás, instituições brasileiras em estudos recentes, como o SEBRAE e o IMAFLORA, que ao se unirem à pesquisadores da ESALQ-USP e da Universidade de Oxford, acabaram por encontrar uma correlação entre a saúde financeira e o desempenho socioambiental de produtores rurais, e que tal correlação apontaria uma tendência de que um melhor desempenho socioambiental estaria diretamente associado a uma maior saúde financeira.

Afinal, um produtor com melhor desempenho socioambiental tende a ser um cliente com menor risco e melhor capacidade de pagamento, beneficiando então, o ente financiador, o produtor rural e o próprio meio ambiente. ${ }^{24}$

\section{CONCLUSÃO}

O crédito rural, diante da temática exposta pelo presente estudo, revela sua enorme importância e seus efeitos, com a sua finalidade de prover avanços no campo, fortalecendo o produtor rural e a produção agropecuária no país.

Contudo, tal incremento necessita de certa responsabilidade por parte dos cedentes, no que tange as questões socioambientais, sob pena de prezar pelo desenvolvimento econômico e social do meio rural, sem ponderar pela sustentabilidade do meio ambiente ecologicamente equilibrado.

Logo, tais investimentos e inovações devem ser ambientalmente responsáveis, vinculando-se a concessão do crédito aos elementos de sustentabilidade positivados pela Lei maior, em atenção também às próprias experiências já sentidas pelas entidades privadas que adotaram as políticas socioambientais em suas relações creditícias.

O que se constata é a evolução do instituto que de uma anterior primazia pelo desenvolvimento econômico social do campo, passou a tratar também da noção de sustentabilidade a partir da criação dos programas de auxílio à agricultura familiar.

Porém, em virtude de uma grande fragilidade técnica e assistencial das políticas públicas, vê-se que tal evolução possa ocorrer com certa lentidão, em contrapartida das

\footnotetext{
${ }^{23}$ BINI, Dienice; PINTO, Luis Fernando Guedes; MIRANDA, Sílvia H. G. de; VIAN, Carlos; AMARAL, Luiz Fernando do. A sustentabilidade é um bom negócio para a agricultura / Crédito pode fazer a diferença para a sustentabilidade da agropecuária. In: Sustentabilidade em debate, $n^{\circ} .3$ - Piracicaba, SP: Imaflora, 2016. p. 18.

${ }^{24}$ Ibidem. p. 17
} 
experiências privadas, como do Rabobank e do SEBRAE, que demonstraram o potencial do crédito e da assistência técnica na promoção da sustentabilidade no campo.

Embora o modelo atual ainda não seja o ideal, ante a parca incidência dos preceitos de sustentabilidade ao considerarmos a globalidade dos financiamentos concedidos, o que se conclui é que, cada vez mais, as instituições cedentes de crédito rural se tornarão ambientalmente responsáveis e prezarão pela sua imagem, analisando os riscos decorrentes do fomento de uma atividade, prezando por empreendimentos que obedeçam aos preceitos da sustentabilidade.

\section{REFERÊNCIAS BIBLIOGRÁFICAS}

BRASIL. Presidência da República. Lei $\mathbf{n}^{0}$ 4.829, de 5 de novembro de 1965. Institucionaliza o crédito rural. Brasília, 5 de novembro de 1965. Disponível em: <http://www.planalto.gov.br/ccivil_03/leis/L4829.htm> Acesso em: 1 set 2016.

Lei $\mathrm{n}^{\circ}$ 454, de 9 de julho de 1937. Autoriza o Tesouro Nacional a subscrever novas ações do Banco do Brasil, até a importância de 100.000:000\$000, e a emitir "bonus" para financiamento da agricultura, creação e outras indústrias. Disponível em <http://www.planalto.gov.br/ccivil_03/LEIS/1930-1949/L0454.htm>. Acesso em 1 set 2016.

Presidência da República. Lei $\mathbf{n}^{\mathbf{0}}$. 8.171, de 17 de janeiro de 1991. Dispõe sobre a política agrícola. Brasília, 17 de janeiro de 1991. Disponível em: <http://www.planalto.gov.br/ccivil_03/leis/L8171.htm>Acesso em: 10 jul. 2016. 
Decreto $n^{0}$ 22.626, de 7 de abril de 1933. Dispõe sobre os juros nos contratos e da

outras providencias.

Disponível

em

<http://www.planalto.gov.br/ccivil_03/decreto/d22626.htm>. Acesso em 1 set 2016.

Constituição da República Federativa do Brasil de 1988. Disponível em <http://www.planalto.gov.br/ccivil_03/constituicao/constituicaocompilado.htm>. Acesso em 1 set 2016 .

Decreto-Lei 4657, de 4 de setembro de 1942. Acesso em <http://www.planalto.gov.br/ccivil_03/decreto-lei/Del4657compilado.htm>. Acesso em 1 set 2016.

BINI, Dienice; PINTO, Luis Fernando Guedes; MIRANDA, Sílvia H. G. de; VIAN, Carlos;

AMARAL, Luiz Fernando do. A sustentabilidade é um bom negócio para a agricultura / Crédito pode fazer a diferença para a sustentabilidade da agropecuária. Sustentabilidade em debate, $n^{\circ} .3$ - Piracicaba, SP: Imaflora, 2016. p. 4-24.

ALBUQUERQUE, Marcos Pradode. Crédito rural. Cuiabá: Ed. UFMT, 1995.

DUARTE, Clarice Seixas. O ciclo das políticas públicas. In: SMANIO, GianpaoloPoggio et BERTOLIN, Patrícia Tuma Martins (Orgs.). O direito e as políticas públicas no Brasil. São Paulo: Atlas, 2013. p. 16-43.

IGARI, Alexandre T.; PIVELLO, Vânia R..Crédito rural e código florestal: irmãos como Caim e Abel. In: Ambiente \& Sociedade, São Paulo, v.14, n.1, 2011. p. 133-150

MARQUES, Benedito Ferreira. Direito agrário brasileiro. 11. ed. rev. e ampl. São Paulo: Atlas, 2015. P.153-164. 
PEREIRA, Lutero de Paiva. Crédito rural. In: QUEIROZ, João Eduardo Lopes et SANTOS, Márcia Walquiria Batista dos (Coords.). Direito do agronegócio. 2. ed. ampl. Belo Horizonte: Fórum, 2011. P.555-576.

REZENDE, Gervásio Castro de. Políticas trabalhista, fundiária e de crédito agrícola no Brasiluma avaliação crítica. In: Rev. Econ. Sociol. Rural, Brasília, v. 44, n. 1, p. 47-78, Mar. 2006.

RIO GRANDE DO SUL. Tribunal de Justiça. Recurso de Apelação Cível no . 70052268166, Apelante: Estado do Rio Grande do Sul. Apelado: Helenita Regina Pfingstag e Outros. Porto Alegre, 24 de outubro de 2013. Disponível em: <http://tjrs.jusbrasil.com.br/jurisprudencia/113446540/apelacao-civel-ac-70052268166-rs/inteiro-teor113446550>. Acesso em: 20 jun. 2016.

RUFINO, Gislaine Paes Carion; ARANA, Alba Regina Azevedo. Risco ambiental e financeiro nas instituições bancárias do pontal do Paranapanema. Colloquium Humanarum, vol. 11, n. Especial, Jul-Dez 2014, p. 308-315.

SANTILLI, Juliana. A agrodiversidade e direitos dos agricultores: regime jurídico internacional e sua implementação no Brasil. In: BARROSO, Lucas Abreu, MANIGLIA, Elisabete, MIRANDA, Alcir Gursen de (Orgs.). A lei agrária nova: biblioteca científica de direito agrário, agroambiental, agroalimentar e do agronegócio. Vol. III. Curitiba: Juruá, 2012. p. 251-283. 
SEVERO, Patrícia Schneider. Sustentabilidade no setor rural a partir do uso do crédito e de técnicas cooperativas na região sul do Rio Grande do Sul. Dissertação de Mestrado, Programa de Pós-Graduação da Escola de Gestão e Negócios. Universidade do Vale do Rio dos Sinos. Porto Alegre. 2014

SILVA, C. F. Estatuto da terra. In Motta, M., Org. Dicionário da Terra. Rio de Janeiro: Editora Civilização Brasileira, 2005, pp. 198-200.

VEIGA, J. E. da. O desenvolvimento agrícola: uma visão histórica. São Paulo:Editora Hucitec, 1992.

WEISS, Edith Brown. Our rights and obligations to future generations for the environment. The American Journal of International Law, vol. 84, n.1, jan. 1990. Pag.40-43

WOJCIECHOWSKI, Ruan Cristian; LEITE, Anderson; SEHNEM, Simone; BERNARDY, Rógis. Análise da concessão de crédito rural pelo BNDES vinculado aos elementos de sustentabilidade.Revista Estudos do CEPE, Santa Cruz do Sul, n. 40, P. 137-167. 